\title{
Pathway of Free Fatty Acid Oxidation in Human Subjects Implications for Tracer Studies
}

Labros S. Sidossis, Andrew R. Coggan, Amalia Gastaldelli, and Robert R. Wolfe

Metabolism Unit, Shriners Burns Institute, and Departments of Anesthesiology and Surgery, University of Texas Medical Branch, Galveston, Texas 77550

\begin{abstract}
To determine the pathway of plasma FFA oxidation and the site(s) of label fixation observed during infusion of FFA tracers, $\left[1-{ }^{13} \mathrm{C}\right]$ palmitate and $\left[1-{ }^{14} \mathrm{C}\right]$ acetate were infused intravenously for $3 \mathrm{~h}$ in five volunteers. Breath ${ }^{13} \mathrm{CO}_{2}$ enrichment and ${ }^{14} \mathrm{CO}_{2}$ specific activity were followed for $6 \mathrm{~h}$ to determine the labeled $\mathrm{CO}_{2}$ decay rates. Acetate enters directly into the TCA cycle; hence, if palmitate transits a large lipid pool before oxidation, ${ }^{13} \mathrm{CO}_{2}$ enrichment (from palmitate) should decay slower than ${ }^{14} \mathrm{CO}_{2}$ specific activity (from acetate). Breath ${ }^{13} \mathrm{CO}_{2}$ enrichment and ${ }^{14} \mathrm{CO}_{2}$ specific activity decayed at a similar rate after stopping the tracer infusions (half-lives of ${ }^{13} \mathrm{CO}_{2}$ and ${ }^{14} \mathrm{CO}_{2}$ decay: mean [ $\pm \mathrm{SE}$ ] 106.6 $\pm 8.9 \mathrm{~min}$, and $96.9 \pm 6.0 \mathrm{~min}$, respectively, $P=\mathrm{NS}$ ), which suggests that palmitate enters the TCA cycle directly and that label fixation occurs after citrate synthesis. Significant label fixation was shown in plasma glutamate/glutamine and lactate/pyruvate during infusion of either [1,2${ }^{13} \mathrm{C}$ ] acetate or $\left[\mathrm{U}-{ }^{13} \mathrm{C}\right.$ ]palmitate, suggesting that TCA cycle exchange reactions are at least partly responsible for label fixation. This was consistent with our finding that the halflives of ${ }^{13} \mathrm{CO}_{2}$ enrichment and ${ }^{14} \mathrm{CO}_{2}$ specific activity decreased significantly during exercise to $14.4 \pm 3 \mathrm{~min}$ and $16.8 \pm 1 \mathrm{~min}$, respectively, since exercise significantly increases the rate of the TCA cycle in relation to that of the TCA cycle exchange reactions. We conclude that plasma FFA entering cells destined to be oxidized are directly oxidized and that tracer estimates of plasma FFA oxidation will underestimate the true value unless account is taken of the extent of label fixation. (J. Clin. Invest. 1995. 95:278284.) Key words: exercise $\bullet$ isotopes $\bullet$ tricarboxylic acid cycle - triacylglycerols • acetate
\end{abstract}

\section{Introduction}

Tracer methodology has been used in a variety of physiological conditions to estimate the rate of plasma FFA oxidation and,

Portions of this work have appeared in abstract form (FASEB [Fed. Am. Soc. Exp. Biol.] 8: 701a).

Address correspondence to Robert R. Wolfe, Chief, Metabolism Unit, Shriners Burns Institute, 815 Market St, University of Texas Medical Branch, Galveston, TX 77555-1220. Phone: 409-770-6605; FAX: 409770-6825.

Received for publication 23 June 1994 and in revised form 9 September 1994.

\footnotetext{
J. Clin. Invest.

(C) The American Society for Clinical Investigation, Inc 0021-9738/95/01/0278/07 \$2.00

Volume 95, January 1995, 278-284
}

in combination with indirect calorimetry, in attempts to differentiate between the oxidation of fatty acids that have come from the blood and those that have been directly oxidized in the same cell in which they were stored ("intracellular fatty acids") (e.g., references 1-10). These studies suggest that as much as $70 \%$ of total fat oxidation comes from intracellular fatty acids $(1-12)$, and based on these results a potential role of intracellularly stored fatty acids in the regulation of fatty acid oxidation has been proposed (5). However, the validity of tracer estimates of plasma fatty acid oxidation has been questioned, based on observations of significant label fixation beyond that explained by bicarbonate kinetics, during infusion of fatty acid tracers in normal volunteers (13). Label fixation was thought to result from incorporation of the label into the lipid pool of the cell, via esterification of the infused fatty acid tracers before being oxidized $(10,14,15)$. The intracellular lipid pool is large and its turnover rate relatively slow. Thus, if this hypothesis is correct, it is unlikely that the intracellular fatty acyl-CoA pool, which is the true precursor pool for oxidation, would achieve isotopic steady state within the time frame of most experiments (i.e., 1-3 h). The fatty acid enrichment in plasma would therefore be higher than the enrichment of the precursor pool for oxidation, not because of possible dilution of the tracer by fatty acids originating from intracellularly stored lipids, but rather due to the time required for the intracellular lipid pool to equilibrate. In this circumstance, the use of the higher enrichment of plasma FFA in the calculation of oxidation will result in the underestimation of the true plasma FFA oxidation rate.

An alternative possibility could explain the label fixation observed during infusion of fatty acid tracers (16-18). Two $\mathrm{CO}_{2}$ molecules are produced for every acetyl-CoA molecule that enters the TCA cycle. However, if one or both carbons of the acetyl-CoA molecule are labeled there is a chance that not all of the label in acetyl-CoA will end up in $\mathrm{CO}_{2}$ as a result of TCA cycle activity, thereby resulting in the underestimation of the true oxidation rate. This could occur if label is lost through exchange reactions in the TCA cycle, as schematically shown in Fig. 1. By exchange reactions we refer to a net movement of tracer occurring in the setting of constant pool sizes of both substrate and product. Exchange of label with unlabeled carbon could occur in the liver mitochondria, where the oxaloacetate $(\mathrm{OAA})^{1}$ pool is common to both the gluconeogenic and TCA cycle pathways. Thus, label can be incorporated into phosphoenolpyruvate (PEP), pyruvate, and eventually glucose. Furthermore, label can be lost from $\alpha$-ketoglutarate to glutamate and glutamine, a reaction that can take place throughout the body. In this case the label will end up in the body's amino acid/ protein pool instead of $\mathrm{CO}_{2}$. It is also possible that label could

\footnotetext{
1. Abbreviations used in this paper: OAA, oxaloacetate; PEP, phosphoenolpyruvate; $\mathrm{Ra}$, rate of appearance; TTR, tracer-tracee ratio.
} 


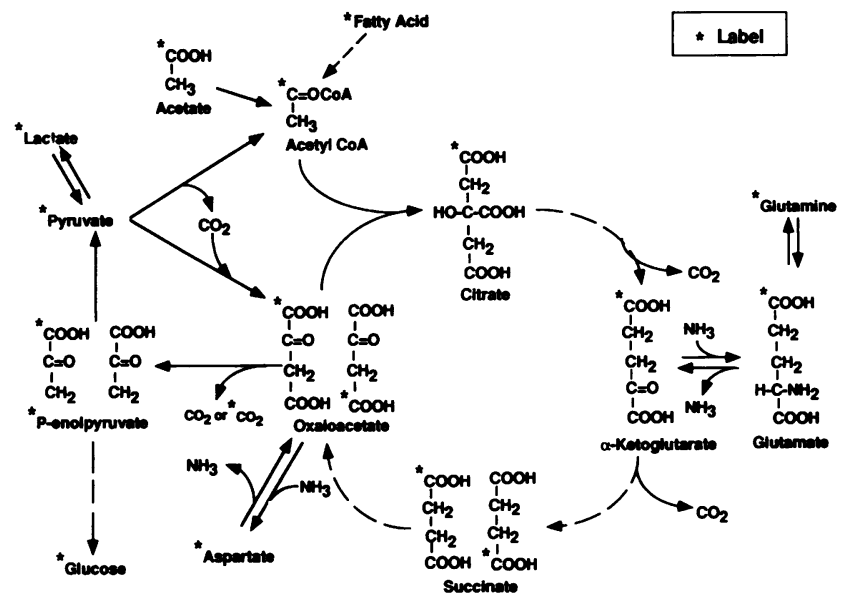

Figure 1. Schematic diagram indicating the possible fates of labeled carbon after it has entered the TCA cycle. Two prominent pathways for exchange (i.e., from $\alpha$-ketoglutarate to glutamate and glutamine, and from OAA to PEP) are shown in detail.

exchange from OAA to aspartate. These pathways are well established from studies in vitro $(16,17)$ and in vivo $(19-21)$. If indeed label fixation during carbon-labeled fatty acid infusion is the result of exchange reactions in the TCA cycle, and not due to tracer incorporation into the lipid pool of the cell, then, given the small size of the intracellular fatty acyl-CoA pool ( 8 , 22 ), an isotopic equilibrium in the intracellular precursor pool for oxidation could be rapidly achieved. In this case the use of plasma fatty acid enrichment in the oxidation calculations would be appropriate, and thus, tracer estimates of fatty acid oxidation would probably be accurate, provided that the extent of label fixation could be determined and incorporated into the calculations in a manner analogous to the current use of bicarbonate correction factor $(23,24)$.

To address these issues we have performed three separate experiments. First, we have infused $\left[1-{ }^{13} \mathrm{C}\right]$ palmitate and [1${ }^{14} \mathrm{C}$ ] acetate for $3 \mathrm{~h}$ in normal volunteers (protocol 1 ). The breath ${ }^{13} \mathrm{CO}_{2}$ enrichment (from the oxidation of $\left[1-{ }^{13} \mathrm{C}\right]-$ palmitate) and the specific activity of ${ }^{14} \mathrm{CO}_{2}$ (from the oxidation of $\left[1-{ }^{14} \mathrm{C}\right]$ acetate) were measured for $6 \mathrm{~h}$ after stopping the infusions to determine the decay rate of labeled $\mathrm{CO}_{2}$. Acetate, as acetyl-CoA, enters directly into the TCA cycle without being incorporated into fat. Thus, if label is fixed before the entrance of labeled acetyl-CoA into the TCA cycle (e.g., in the triacylglycerol ( $\mathrm{Tg}$ ) pool ), then ${ }^{13} \mathrm{CO}_{2}$ enrichment from labeled palmitate should decay at a slower rate than ${ }^{14} \mathrm{CO}_{2}$ specific activity from labeled acetate. On the other hand, if the decay rates of ${ }^{13} \mathrm{CO}_{2}$ enrichment and ${ }^{14} \mathrm{CO}_{2}$ specific activity are similar, it would indicate that label fixation occurs after labeled acetylCoA has entered the TCA cycle. Second, to confirm directly the role of exchange reactions in label fixation, we measured plasma glutamate/glutamine and lactate/pyruvate enrichment during infusion of $\left[1,2-{ }^{13} \mathrm{C}\right]$ acetate (protocol 2) and $\left[\mathrm{U}-{ }^{13} \mathrm{C}\right]-$ palmitate (protocol 3). If plasma glutamate/glutamine and lactate/pyruvate enrichment increase, it would indicate that label is fixed via exchange reactions in the TCA cycle, since these are the only pathways by which label from $\left[1,2-{ }^{13} \mathrm{C}\right]$ acetate and $\left[\mathrm{U}-{ }^{13} \mathrm{C}\right]$ palmitate could end up in plasma glutamate/glutamine and lactate/pyruvate. Finally, we have further tested the role of the exchange reactions in the TCA cycle by determining the labeled $\mathrm{CO}_{2}$ decay rates after stopping $\left[1-{ }^{14} \mathrm{C}\right]$ acetate and $\left[1-{ }^{13} \mathrm{C}\right]$ palmitate infusions during exercise (protocol 4 ). Exercise substantially increases the rate of the TCA cycle, yet the rate of TCA cycle exchange reactions would not be expected to increase correspondingly $(25,26)$. Thus, if TCA cycle exchange reactions are the major site of label fixation, palmitateand acetate-derived labeled $\mathrm{CO}_{2}$ would decay significantly faster during exercise as compared to rest. On the other hand, if label fixation is the result of esterification and storage of fatty acid tracers into the lipid pool of the cell, then only a modest increase in palmitate-derived ${ }^{13} \mathrm{CO}_{2}$ decay rate should be expected, reflecting the two to threefold increase in FFA flux that results from exercise (27).

\section{Methods}

Volunteers. 12 volunteers, 4 women and 8 men (age $29 \pm 6$ y, body wt $69 \pm 8 \mathrm{~kg}$ ), participated in one or more protocols. The number of volunteers in each protocol is specified below. All volunteers were healthy, as indicated by comprehensive history, physical examination, and standard blood and urine tests, and consented to participate in this study, which was approved by the Institutional Review Board and the Clinical Research Center of the University of Texas Medical Branch at Galveston.

All experiments were performed in the morning, after the volunteers had fasted overnight (i.e., $12 \mathrm{~h}$ ). Teflon catheters were placed percutaneously into an antecubital vein for isotope infusion and into a contralateral dorsal hand vein, which was heated, for sampling of arterialized venous blood. The catheters were kept patent by controlled infusion of $0.9 \%$ $\mathrm{NaCl}$. The volunteers rested for 15-30 min after catheter placement, at which time one of the following four experimental protocols was performed.

Protocol 1: labeled $\mathrm{CO}_{2}$ decay studies at rest $(n=5)$. In this protocol the decay rates of labeled $\mathrm{CO}_{2}$ after stopping the infusion of $\left[1-{ }^{13} \mathrm{C}\right]$ palmitate and $\left[1-{ }^{14} \mathrm{C}\right]$ acetate were determined. A primed $(5.0$ $\mathrm{nCi} / \mathrm{kg})$, constant $\left(0.2 \mathrm{nCi} \cdot \mathrm{kg}^{-1} \cdot \mathrm{min}^{-1}\right)$ infusion of $\left[1-{ }^{14} \mathrm{C}\right]$ acetate (Dupont-NEN, Boston, MA) dissolved in $0.9 \% \mathrm{NaCl}$, and a constant $\left(0.05 \mu \mathrm{mol} \cdot \mathrm{kg}^{-1} \cdot \mathrm{min}^{-1}\right)$ infusion of $\left[1{ }^{13} \mathrm{C}\right]$ palmitate $(99 \%$ enriched, MSD Isotopes Div., Montreal, Canada) bound to 5\% human albumin (Alpha Therapeutic Corporation, Los Angeles, CA) were started and maintained in human volunteers for $3 \mathrm{~h}$ using calibrated syringe pumps. The exact infusion rates were determined by measuring the concentrations of the isotopes in the infusates and multiplying those values by the infusion rates. Priming doses of $\mathrm{NaH}^{13} \mathrm{CO}_{3}\left(1.2 \mu \mathrm{mol} \cdot \mathrm{kg}^{-1}\right)$ and $\mathrm{NaH}^{14} \mathrm{CO}_{3}\left(10 \mathrm{nCi} \cdot \mathrm{kg}^{-1}\right)$ were given at the beginning of the studies, diluted in $0.01 \mathrm{~N} \mathrm{NaOH}$. After $3 \mathrm{~h}$, the infusions were discontinued and the volunteers rested for $6 \mathrm{~h}$ more.

Blood samples were obtained before tracer infusion, at 160, 170, and 180 min of infusion, and $1,2,3,4,5,8,10,20,30,40,50$, and $60 \mathrm{~min}$ after stopping the tracer infusion for determination of plasma palmitate carbon enrichment. Breath samples were obtained before tracer infusion, 160, 170, and $180 \mathrm{~min}$ after the beginning of infusion, $2,4,6,8,10,20,30,40,50$, and $60 \mathrm{~min}$ after stopping the infusion and every $30 \mathrm{~min}$ thereafter for the remainder of the study period for measurement of ${ }^{13} \mathrm{CO}_{2}$ enrichment and ${ }^{14} \mathrm{CO}_{2}$ specific activity.

Protocol 2: doubly labeled acetate infusion $(n=5)$. This protocol was designed $(a)$ to test the assumption that acetate directly enters the TCA cycle, and $(b)$ to quantify the extent of label fixation via TCA cycle exchange reactions, which represents nonoxidative loss of label during infusion of acetate tracers. To quantify the extent of label fixation, not only is the rate at which the enrichment increases in glutamate/ glutamine and lactate/pyruvate during the $\left[1,2{ }^{13} \mathrm{C}\right]$ acetate infusion required, but also the kinetics of these pools must be quantified. Thus, in this protocol, $d_{4}$-glutamate was given as a bolus $\left(50 \mu \mathrm{mol} \cdot \mathrm{kg}^{-1}\right)$ at the start of the $\left[1,2-{ }^{13} \mathrm{C}\right]$ acetate infusion $\left(2.5 \mu \mathrm{mol} \cdot \mathrm{kg}^{-1} \cdot \mathrm{min}^{-1}\right.$, prime $\left.62.5 \mu \mathrm{mol} \cdot \mathrm{kg}^{-1}\right)$. The acetate infusion was maintained for $30 \mathrm{~min}$, after which a bolus of $\left[\mathrm{U}^{13} \mathrm{C}\right]$ pyruvate $\left(30.5 \mu \mathrm{mol} \cdot \mathrm{kg}^{-1}\right)$ was given 
to quantify the lactate/pyruvate kinetics. The pyruvate tracer enables quantification of the total lactate/pyruvate pool because of the rapid exchange between lactate and pyruvate (28), and the glutamate tracer enables quantification of both the glutamate and glutamine pools because these compounds are analytically indistinguishable using the nitrogenacetyl- $n$-propyl ester derivative (see Assays). The pyruvate bolus was delayed until the end of the acetate infusion because it would have interfered with the ${ }^{13} \mathrm{C}$ incorporation data during the acetate infusion. Residual acetate tracer, on the other hand, had no effect on the calculation of pyruvate kinetics because of the mass difference of the carbon in the tracers. Blood samples were obtained before tracer infusion and $2,4,6,10,15,17,20,25$, and $30 \mathrm{~min}$ after the start of $\left[1,2-{ }^{13} \mathrm{C}\right]$ acetate infusion. The sampling schedule was the same following the $\left[\mathrm{U}_{-}{ }^{13} \mathrm{C}\right]-$ pyruvate injection.

Protocol 3: uniformly labeled palmitate infusion $(n=2)$. To test the hypotheses that $(a)$ at least part of the plasma FFA directly enter the TCA cycle without transiting premitochondrial pool(s), and $(b)$ at least part of the label fixation observed during infusion of fatty acid tracers occurs via exchange reactions in the TCA cycle, a primed $(2.3$ $\left.\mu \mathrm{mol} \cdot \mathrm{kg}^{-1}\right)$ constant $\left(0.23 \mu \mathrm{mol} \cdot \mathrm{kg}^{-1} \cdot \mathrm{min}^{-1}\right)$ infusion of $\left[\mathrm{U}-{ }^{13} \mathrm{C}\right]-$ palmitate (98\% enriched; CIL, Woburn, MA), bound to 5\% human albumin was started and maintained for $40 \mathrm{~min}$. Blood samples were obtained before the tracer infusion, and at $2,4,6,10,15,20,25,30$, 35 , and 40 min after the start of tracer infusion, for determination of plasma glutamate and lactate/pyruvate enrichments. Breath samples for the determination of ${ }^{13} \mathrm{CO}_{2}$ enrichment were obtained before the start of tracer infusions and $2,4,6,8,10,12,15,20,25,30,35$, and $40 \mathrm{~min}$ after the start of infusions.

Protocol 4: labeled $\mathrm{CO}_{2}$ decay studies during exercise $(n=5)$. These exercise experiments were performed to test the hypothesis that an increase in the rate of the TCA cycle would decrease the relative proportion of tracer lost to exchange reactions, thereby minimizing the time delay in decay of ${ }^{13} \mathrm{CO}_{2}$ enrichment after the infusion of $\left[1-{ }^{13} \mathrm{C}\right]-$ palmitate is stopped. Confirmation of this hypothesis would support the contention that TCA cycle exchange reactions are the major site of label fixation observed during infusion of fatty acid tracers. After catheter placement the volunteers sat quietly on a cycle ergometer and 15-30 min later blood and breath samples were obtained for the determination of background enrichments. Immediately after, exercise at $40 \pm 10 \% \mathrm{VO}_{2}$ peak was started and continued for $2 \mathrm{~h}$. The volunteers' $\mathrm{VO}_{2}$ peak were determined 1 wk earlier using a continuous exercise protocol during which power output was increased by $25 \mathrm{~W}$ every 2 min until fatigue. At the start of exercise an infusion of $\mathrm{NaH}^{14} \mathrm{CO}_{3}\left(20.0 \mathrm{nCi} \cdot \mathrm{kg}^{-1}\right.$ prime, $1.0 \mathrm{nCi} \cdot \mathrm{kg}^{-1} \cdot \mathrm{min}^{-1}$ constant infusion $)$ and $\left[1{ }^{-13} \mathrm{C}\right]$ palmitate $(0.12$ $\mu \mathrm{mol} \cdot \mathrm{kg}^{-1} \cdot \mathrm{min}^{-1}$ constant infusion $)$, or, on a second occasion, an infusion of $\left[1-{ }^{14} \mathrm{C}\right]$ acetate $\left(20 \mathrm{nCi} \cdot \mathrm{kg}^{-1}\right.$ prime, $1.0 \mathrm{nCi} \cdot \mathrm{kg}^{-1} \cdot \mathrm{min}^{-1}$ constant infusion) was started and maintained for the first hour of exercise Priming doses of $\mathrm{NaH}^{13} \mathrm{CO}_{3}\left(5.0 \mu \mathrm{mol} \cdot \mathrm{kg}^{-1}\right.$, when $\left[1{ }^{13} \mathrm{C}\right]$ palmitate was infused) and $\mathrm{NaH}^{14} \mathrm{CO}_{3}\left(20 \mathrm{nCi} \cdot \mathrm{kg}^{-1}\right.$, when $\left[1-{ }^{14} \mathrm{C}\right]$ acetate was infused) were given immediately preceding the tracer infusion. After 1 $\mathrm{h}$, the infusions were stopped and the volunteers continued to cycle for an additional $1 \mathrm{~h}$.

Blood samples were obtained at $45,50,55$, and $60 \mathrm{~min}$ of infusion and $0.5,1,1.5,2,2.5,3,4,5,8,10,15,20$, and $30 \mathrm{~min}$ after stopping of the tracer infusion for measurements of plasma palmitate enrichment. Breath samples for the determination of ${ }^{13} \mathrm{CO}_{2}$ enrichment and ${ }^{14} \mathrm{CO}_{2}$ specific activity were obtained at 50,55, and $60 \mathrm{~min}$ after the beginning of infusion and 1, 2, 3, 4, 5, 6, 7, 8, 9, 10, 15, 20, 30, 40, 50, and 60 min after the infusion was stopped.

Assays. Expired air for measurement of ${ }^{14} \mathrm{CO}_{2}$ specific activity, was collected in 3-liter anesthesia bags and $\mathrm{CO}_{2}$ was trapped by bubbling through a 1:4:9 solution of phenolphthalein $(0.1 \%$ solution; Fisher Scientific Co., Fair Lawn, NJ), benzethonium hydroxide (1.0 M solution; Sigma Chemical Co., St. Louis, MO), and absolute ethanol to trap exactly $1 \mathrm{mmol}$ of $\mathrm{CO}_{2}$. Scintillation fluid $(10 \mathrm{ml}$ of toluene, $0.04 \%$ 2,5-diphenyl-oxazole; Sigma Chemical Co.) was added immediately in the vial and ${ }^{14} \mathrm{CO}_{2}$ specific activity (disintegrations $\cdot \mathrm{min}^{-1} \cdot \mathrm{mmol}^{-1}$ ) was determined using liquid scintillation counting (29). $20 \mathrm{ml}$ of expired air was injected into evacuated tubes for determination of ${ }^{13} \mathrm{CO}_{2} /{ }^{12} \mathrm{CO}_{2}$. Briefly, $\mathrm{CO}_{2}$ was isolated from the breath samples before analysis by isotope ratio-mass spectrometry (IRMS) by passage through a water trap followed by condensation in a liquid nitrogen trap to allow other gases to be evacuated. The ${ }^{13} \mathrm{CO}_{2} /{ }^{12} \mathrm{CO}_{2}$ was then determined with a triple-collector IRMS (SIRA VG; Isotech, Cheshire, UK). The ratio is reported in units of tracer-tracee ratio (TTR) that is defined as: TTR $=\left({ }^{13} \mathrm{C} /{ }^{12} \mathrm{C}\right) \mathrm{sa}-\left({ }^{13} \mathrm{C} /{ }^{12} \mathrm{C}\right)$ ref $-\left[\left({ }^{13} \mathrm{C} /{ }^{12} \mathrm{C}\right) \mathrm{bk}-\left({ }^{13} \mathrm{C} /{ }^{12} \mathrm{C}\right)\right.$ ref $]$, where $\mathrm{sa}=$ sample, ref $=$ reference gas, and $\mathrm{bk}=$ baseline sample.

Blood samples were collected into prechilled tubes containing sodium heparin, and plasma was separated immediately by centrifugation and frozen until further processing. Plasma palmitate enrichment was determined by following previously described procedures (30). Briefly, FFA were extracted from plasma, isolated by thin-layer chromatography, and converted to their methyl esters. The isotopic enrichment of palmitate was determined by gas chromatography mass spectrometry (GCMS) (5992; Hewlett-Packard Co., Palo Alto, CA), by selectively monitoring ions mass-to-charge $(\mathrm{m} / \mathrm{e})$ of 270 and 271.

For determination of glutamate/glutamine enrichment (protocol 2) the proteins in plasma were precipitated, the amino acids were separated from the protein-free supernatant, and the nitrogen-acetyl- $n$-propyl esters were prepared and analyzed by GCMS, selectively monitoring ions at $\mathrm{m} / \mathrm{e} 274$, and $276(30)$. This derivatization procedure causes loss of the amide nitrogen of glutamine, but all carbons of glutamate are retained. Thus, with this analytical approach we pool glutamine and glutamate carbon enrichment, which is appropriate since we are considering them in essence a single biological pool.

To measure plasma lactate enrichment $1.5 \mathrm{ml}$ of freshly drawn whole blood was added to ethyl acetate $/ \mathrm{HCl}$ solution and immediately centrifuged for $10 \mathrm{~min}$ at $4^{\circ} \mathrm{C}$. After treatment with sodium sulfate the Tristrimethylsilyl derivative of lactate was analyzed using a GCMS, selectively monitoring ions at $\mathrm{m} / \mathrm{e} 219$ and 221 . Since lactate and pyruvate enrichment are in equilibrium intracellularly (31), an increase in lactate enrichment, during the infusion of $\left[1,2-{ }^{13} \mathrm{C}\right]$ acetate and $\left[\mathrm{U}-{ }^{13} \mathrm{C}\right]$ palmitate, would indicate label transfer from OAA to PEP and eventually pyruvate.

Glutamate carbon enrichment in protocol 3 was measured on an IRMS, which is significantly more sensitive than the GCMS, because the anticipated plasma glutamate enrichment was very low. Plasma glutamate was first isolated by high pressure liquid chromatography. The separation was carried out on a 2150 solvent delivery system, equipped with a 2152 LC controller. Confirmation of the purity of the aliquot containing glutamate was performed on a 2248 solvent delivery system equipped with a 2144 fluorescent detector (all from LKB, Bromma, Sweden). Glutamate carbon enrichment was determined after combustion on a SIRA VG triple-collector IRMS (Isotech). With this approach glutamine is not included in the analysis, as glutamate is specifically isolated by high pressure liquid chromatography without any derivatization and minimal degradation of glutamine to glutamate, and total carbon enrichment (as opposed to molecular enrichment) is determined.

Calculations. $\mathrm{CO}_{2}$ decay data were first normalized to the plateau enrichment before the infusion of tracers was stopped ( $100 \%$ at $t=0)$. The decay of enrichment subsequent to stopping the infusion was then fitted using a one or a two exponential model: $y(t)=A o$ $+\sum A_{\mathrm{i}} \mathrm{e}^{\mathrm{kit}}$, where $n=1$ or 2 , with the constraints that $A_{\mathrm{i}}>=0$ and $\sum_{i=1}$

$K_{\mathrm{i}}<=0$. For a specific candidate model with fixed value of $n$, the best fit to the washout data was found using the weighted nonlinear least squares method implemented on MLAB (Civilized Software, Bethesda, MD). The half-life of labeled carbon decay is the time required for the TTR to decay $50 \%$.

Glutamate/glutamine and lactate/pyruvate rate of appearance ( $\mathrm{Ra})$ were determined using a two-compartment model where the appearance and loss of label occurs from the second pool. The enrichment data were fitted as described above, and the kinetic parameters (including $\mathrm{Ra}$ ) were computed using MLAB.

The extent of label fixation via TCA cycle exchange reactions (pro- 


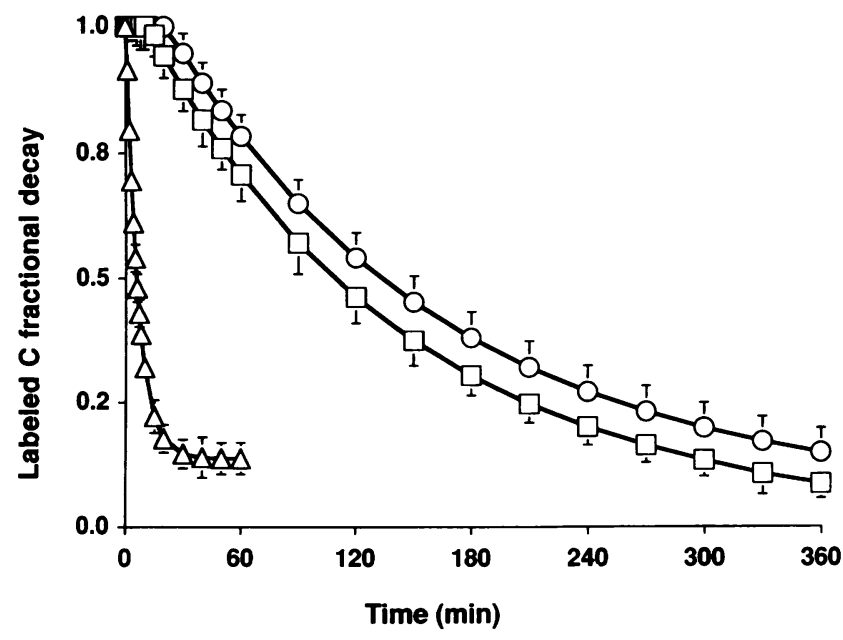

Figure 2. Fractional decay of plasma palmitate enrichment, breath ${ }^{13} \mathrm{CO}_{2}$ enrichment, and breath ${ }^{14} \mathrm{CO}_{2}$ specific activity, after stopping $\left[1-{ }^{13} \mathrm{C}\right]-$ palmitate, and $\left[1-{ }^{14} \mathrm{C}\right]$ acetate infusions at rest (means $\pm \mathrm{SE}$ for five volunteers) (protocol 1). $-\Delta-,\left[{ }^{13} \mathrm{C}\right]$ plasma palmitate; $-\square-$, ${ }^{14} \mathrm{CO}_{2}$ from $\left[1-{ }^{14} \mathrm{C}\right]$ acetate; $-\mathrm{O}-{ }^{13} \mathrm{CO}_{2}$ from $\left[1-{ }^{13} \mathrm{C}\right]$ palmitate.

tocol 2), which represents nonoxidative loss of label into glutamate/ glutamine and lactate/pyruvate, was estimated as follows:

percent labeled carbon from $\left[1,2-{ }^{13} \mathrm{C}\right]$ acetate transferred to glutamate/ glutamine $=$

$\underline{\text { Ra glutamate/glutamine } \times \text { glutamate/glutamine enrichment }}$

$$
2 \times \text { acetate infusion rate }
$$

and

percent labeled carbon from $\left[1,2-{ }^{13} \mathrm{C}\right]$ acetate transferred to lactate/ pyruvate $=$

$\underline{\mathrm{Ra} \text { lactate/pyruvate } \times \text { lactate/pyruvate enrichmen }}$ $2 \times$ acetate infusion rate

The 2 in the denominator is to account for the fact that doubly labeled acetate was infused.

Statistical analysis. Half-lives were compared by the $z$ test, where $z$ is equal to the fraction where the numerator is the difference of the half-lives and the denominator is the standard error of the numerator. Regression analysis (TTR regressed on time) was used to estimate the slope and SE of plasma glutamate/glutamine and lactate/pyruvate enrichment in all protocols. We tested the hypothesis that the slope was zero, for each individual slope, by the $t$ test, and differences between slopes were compared by the $z$ test. Plasma glutamate/glutamine and lactate/pyruvate TTR at each time point was compared to basal via a paired $t$ test.

\section{Results}

Protocol 1. Plasma palmitate enrichment, breath ${ }^{13} \mathrm{CO}_{2}$ enrichment, and breath ${ }^{14} \mathrm{CO}_{2}$ specific activity reached an apparent plateau at the end of $3 \mathrm{~h}$ of $\left[1-{ }^{13} \mathrm{C}\right]$ palmitate and $\left[1-{ }^{14} \mathrm{C}\right]$ acetate infusions in all studies (data not shown).

The pattern of decay of plasma palmitate enrichment, ${ }^{13} \mathrm{CO}_{2}$ enrichment, and ${ }^{14} \mathrm{CO}_{2}$ specific activity, after discontinuation of tracer infusion, are shown in Fig. 2. The half-life of ${ }^{13} \mathrm{CO}_{2}$ excretion, from $\left[1-{ }^{13} \mathrm{C}\right]$ palmitate, was similar to the half-life of ${ }^{14} \mathrm{CO}_{2}$ excretion, from $\left[1-{ }^{14} \mathrm{C}\right]$ acetate, and significantly greater
Table I. Half Lives of Labeled Carbon Decay after Stopping Infusion of Tracers

\begin{tabular}{lcccc}
\hline & $\begin{array}{c}\text { Plasma } \\
{\left[{ }^{13} \mathrm{C}\right] \text { palmitate }}\end{array}$ & $\begin{array}{c}{ }^{13} \mathrm{CO}_{2} \text { (from } \\
{\left[11^{13} \mathrm{C}\right] \text { almitate) }}\end{array}$ & $\begin{array}{c}{ }^{14} \mathrm{CO}_{2} \text { (from } \\
{\left[1^{14}{ }^{14} \mathrm{C}\right] \text { acetate) }}\end{array}$ & $\begin{array}{c}{ }^{14} \mathrm{CO}_{2} \text { (from } \\
\left.\mathrm{NaH}^{14} \mathrm{CO}_{3}\right)\end{array}$ \\
\hline $\begin{array}{l}\text { Rest } \\
\text { (protocol 1) }\end{array}$ & $4.3 \pm 0.4$ & $106.6 \pm 8.9$ & $96.9 \pm 6.0$ & $37 \pm 1^{\ddagger}$ \\
$\begin{array}{c}\text { Exercise } \\
\text { (protocol 4) }\end{array}$ & $1.7 \pm 0.3^{*}$ & $12.2 \pm 2.6^{*}$ & $14.2 \pm 1.1^{*}$ & $5.1 \pm 1.0$ \\
\hline
\end{tabular}

Values are means $\pm \mathrm{SE}$ in $\min .{ }^{*} P<0.001 \mathrm{vs}$ rest, ${ }^{\ddagger}$ from reference 13.

than the half-life of plasma $\left[{ }^{13} \mathrm{C}\right]$ palmitate (Table I). To demonstrate the point that bicarbonate kinetics only partly explain the prolonged ${ }^{13} \mathrm{CO}_{2}$ and ${ }^{14} \mathrm{CO}_{2}$ excretion, the half-life of ${ }^{14} \mathrm{CO}_{2}$ specific activity, from $\mathrm{NaH}^{14} \mathrm{CO}_{3}$ infusion, as reported by Heiling et al. (13) from a similar experimental protocol, is also shown in Table I.

Protocol 2. Consistent with the hypothesis that acetate directly enters into the TCA cycle, plasma glutamate/glutamine and lactate/pyruvate enrichments significantly $(P<0.01)$ increased within $6 \mathrm{~min}$ after the start of $\left[1,2-{ }^{13} \mathrm{C}\right]$ acetate infusion (Fig. 3). Furthermore, both plasma glutamate/glutamine and lactate/pyruvate enrichments continued to increase throughout the experiments, indicating label fixation via exchange reactions in the TCA cycle (Fig. 3). The rates of glutamate/glutamine and lactate/pyruvate appearance were $12.1 \pm 1.0 \mu \mathrm{mol} \cdot \mathrm{kg}^{-1}$. $\mathrm{min}^{-1}$ and $41.2 \pm 4.3 \mu \mathrm{mol} \cdot \mathrm{kg}^{-1} \cdot \mathrm{min}^{-1}$, respectively. Nonoxidative loss of label into glutamate/glutamine and lactate/pyruvate accounted for 9.5 and $4.1 \%$ of acetate label, respectively.

Protocol 3. Plasma glutamate carbon enrichment significantly $(P<0.05)$ increased over the baseline within $6 \mathrm{~min}$ after the start of $\left[\mathrm{U}-{ }^{13} \mathrm{C}\right]$ palmitate infusion, and continued to increase throughout the experiment (Fig. 4). Breath ${ }^{13} \mathrm{CO}_{2}$ enrichment also started to increase shortly after the initiation of tracer infusion (Fig. 4). These results suggest that, like acetate, palmitate also directly enters into the TCA cycle and that TCA cycle exchange reactions are, at least in part, responsible for

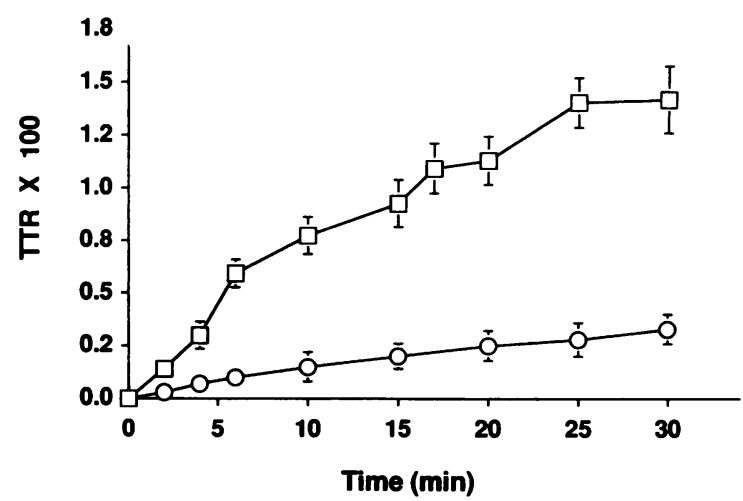

Figure 3. Plasma glutamate/glutamine and lactate/pyruvate enrichments during $30 \mathrm{~min}$ of $\left[1,2-{ }^{13} \mathrm{C}\right]$ acetate infusion at rest (means $\pm \mathrm{SE}$ for five volunteers). The enrichments of both glutamate/glutamine $(-\square-)$ and lactate/pyruvate $(-\circ-)$ significantly $(P<0.01)$ increased over basal within $6 \mathrm{~min}$ after the beginning of $\left[1,2-{ }^{13} \mathrm{C}\right]$ acetate infusion (protocol 2). 


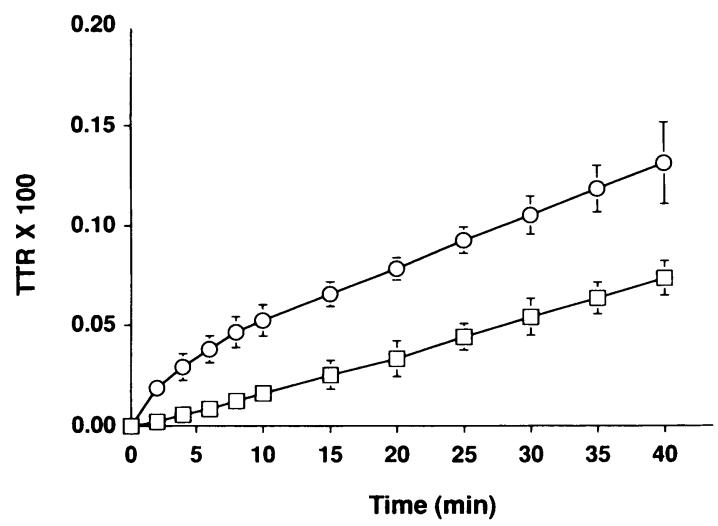

Figure 4. Plasma glutamate carbon enrichment and breath ${ }^{13} \mathrm{CO}_{2}$ enrichment during $40 \mathrm{~min}$ of $\left[\mathrm{U}^{1{ }^{13}} \mathrm{C}\right]$ palmitate infusion at rest (means $\pm \mathrm{SE}$ for two volunteers). Glutamate and ${ }^{13} \mathrm{CO}_{2}$ enrichments significantly ( $P$ $<0.05$ ) increased over basal within $6 \mathrm{~min}$ after the beginning of $\left[\mathrm{U}-{ }^{13} \mathrm{C}\right]$ palmitate infusion (protocol 3),$-\square-$, breath ${ }^{13} \mathrm{CO}_{2}$, - $\mathrm{O}-$, plasma glutamate carbon.

label fixation during infusion of fatty acid tracers. It was not possible to detect significant changes in plasma lactate enrichment due to the low tracer infusion rate used in this protocol.

Protocol 4. Plasma palmitate carbon enrichment, ${ }^{13} \mathrm{CO}_{2}$ enrichment (from the oxidation of $\left[1-{ }^{13} \mathrm{C}\right]$ palmitate), and ${ }^{14} \mathrm{CO}_{2}$ specific activity (from $\mathrm{NaH}^{14} \mathrm{CO}_{3}$ and $\left[1-{ }^{14} \mathrm{C}\right]$ acetate infusions ), reached an apparent plateau at the end of $60 \mathrm{~min}$ of [1${ }^{13} \mathrm{C}$ ] palmitate, $\left[1-{ }^{14} \mathrm{C}\right]$ acetate, and $\mathrm{NaH}^{14} \mathrm{CO}_{3}$ infusion during exercise (data not shown).

The decay curves of labeled carbon after discontinuation of tracer infusion during exercise are shown in Fig. 5. The halflife of plasma $\left[{ }^{13} \mathrm{C}\right]$ palmitate was $1.7 \pm 0.3 \mathrm{~min}$. The half-life of ${ }^{13} \mathrm{CO}_{2}$ excretion, from $\left[1-{ }^{13} \mathrm{C}\right]$ palmitate, was $12.2 \pm 2.6 \mathrm{~min}$, similar to the half-life of ${ }^{14} \mathrm{CO}_{2}$ excretion from $\left[1-{ }^{14} \mathrm{C}\right]$ acetate $(14.2 \pm 1.1, P=\mathrm{NS})$. As was the case at rest, ${ }^{13} \mathrm{CO}_{2}$ enrichment and ${ }^{14} \mathrm{CO}_{2}$ specific activity (from $\left[1-{ }^{14} \mathrm{C}\right]$ acetate) decayed significantly $(P<0.01)$ slower than bicarbonate-derived ${ }^{14} \mathrm{CO}_{2}$ specific activity (Fig. 5), suggesting that bicarbonate kinetics only in part explain label fixation during exercise as during rest.

${ }^{13} \mathrm{CO}_{2}$ (from $\left[1-{ }^{13} \mathrm{C}\right]$ palmitate), and ${ }^{14} \mathrm{CO}_{2}$ specific activity (from $\left[1-{ }^{14} \mathrm{C}\right]$ acetate) decayed significantly $(P<0.01)$ faster during exercise as compared to rest (Table I), in keeping with the notion that exchange reactions in the TCA are the major site of label fixation during fatty acid tracer infusion.

\section{Discussion}

The validity of tracer estimates of plasma FFA oxidation has been questioned based on observations of significant label fixation, beyond that explained by bicarbonate kinetics, during infusion of fatty acid tracers. It has been suggested that the label fixation results from plasma FFA entering cells for oxidation first being esterified into $\mathrm{Tg}$ and temporarily stored in the lipid pool of the cell before oxidation. We found that plasma FFA entering cells destined to be oxidized are transferred directly into the mitochondria without transiting premitochondrial lipid pools (protocol 1). The notion that plasma FFA directly enter the oxidative pathway was confirmed by the findings that label from the infused palmitate was recovered in breath $\mathrm{CO}_{2}$ and plasma glutamate shortly after the start of $\left[\mathrm{U}-{ }^{13} \mathrm{C}\right]$ palmitate

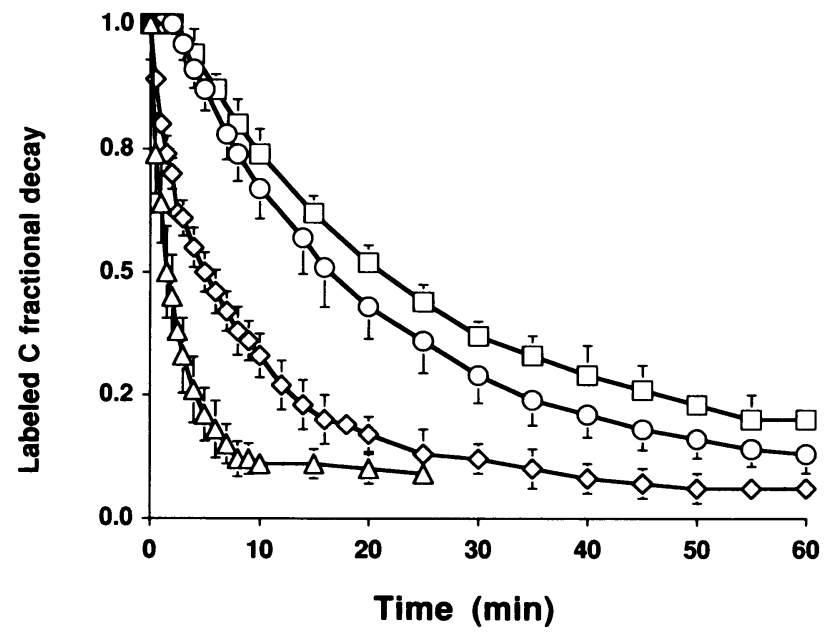

Figure 5. Fractional decay of plasma palmitate enrichment, breath ${ }^{13} \mathrm{CO}_{2}$ enrichment, and breath ${ }^{14} \mathrm{CO}_{2}$ specific activity, after stopping $\left[1-{ }^{13} \mathrm{C}\right]-$ palmitate, $\mathrm{NaH}^{14} \mathrm{CO}_{3}$ and $\left[1-{ }^{14} \mathrm{C}\right]$ acetate infusions during exercise (means \pm SE for three volunteers) (protocol 4$) .-\Delta-,\left[{ }^{13} \mathrm{C}\right]$ plasma palmitate; - $\diamond-,{ }^{14} \mathrm{CO}_{2}$ from $\mathrm{NaH}^{14} \mathrm{CO}_{3} ;-0-,{ }^{13} \mathrm{CO}_{2}$ from $\left[1-{ }^{13} \mathrm{C}\right]$ palmitate; $-\square-,{ }^{14} \mathrm{CO}_{2}$ from $\left[1-{ }^{14} \mathrm{C}\right]$ acetate.

infusion (protocol 3). Furthermore, these findings also indicated that exchange reactions in the TCA cycle were responsible for at least part of the label fixation observed during the infusion of labeled palmitate (protocols 2 and 3 ). In fact, the exercise studies (protocol 4) showed that these exchange reactions are the major sites of label fixation.

The validity of the acetate tracer in our experiment depends on the direct entry of infused acetate into the TCA cycle for oxidation. It has been shown that in the postabsorptive state incorporation of acetate into fatty acids, which is the only other major pathway of acetate metabolism, is virtually zero (32). In addition, our finding that plasma glutamate/glutamine and lactate/pyruvate enrichments significantly increased over basal within 6 min after the initiation of a primed constant infusion of $\left[1,2-{ }^{13} \mathrm{C}\right]$ acetate (Fig. 3 ), strongly suggests that acetate enters directly into the TCA cycle. This is because the only pathway by which label from acetate can end up in glutamate/glutamine and lactate/pyruvate is via exchange reactions occurring after acetate-derived labeled acetyl-CoA has entered the TCA cycle (Fig. 1). In any case, if all infused acetate was not directly oxidized, then the estimation that $14 \%$ of label was lost to glutamate/glutamine and pyruvate/lactate would be too low, thereby strengthening our conclusion regarding the quantitative importance of these pathways.

The focus of this investigation was on the fate of plasma FFA that enter cells destined to be oxidized and not those FFA that are esterified into $\mathrm{Tg}$ and either stored or excreted by the liver in the form of VLDL-Tg. It is well established that at rest $\sim 50 \%$ of plasma FFA taken up by the various tissues of the body are re-esterified for storage (33). Our present finding suggests that the majority of the fatty acids that are oxidized (i.e., $~ 50 \%$ of uptake) are directly transferred into the mitochondria, the site of oxidative decarboxylation. This finding is in contrast to the notion that some $(6,7,14,15,22,34,35)$, or even all ( 10 ) of the plasma FFA entering cells to be oxidized, transit slow intracellular premitochondrial pools before oxidation. This hypothesis was based on observations of incomplete 
oxidation of fatty acid tracers $(6,7,10,14,15,35)$ or was derived from the results of kinetic analyses of the oxidation of labeled fatty acids $(22,34)$. Our conclusion is in agreement, however, with the results from studies in which the arteriovenous difference during exercise of the water soluble metabolites was also quantified during infusion of fatty acid tracers (8, 11). These studies showed that, taken together, $\mathrm{CO}_{2}$ and water soluble radioactivity could account for all of the labeled FFA entering the muscle, suggesting that none of the FFA was stored in the muscle lipid pool before oxidation. If it is true that plasma FFA are directly oxidized then, given the small size of the intracellular fatty acid pool $(8,22)$, an isotopic equilibrium in the intracellular precursor pool for oxidation could be rapidly (i.e., within 1-2 h) achieved, supporting the use of plasma FFA enrichment in the oxidation calculations.

Whereas it appears to be possible to achieve an isotopic equilibrium in precursor (fatty acid) enrichment, there is still a significant problem with the isotopic technique. Thus, during infusion of $\left[1-{ }^{13} \mathrm{C}\right]$ palmitate we, similar to others $(10,13)$, observed significant label fixation, beyond that explained by bicarbonate kinetics. This was evident from the prolonged high rates of palmitate-derived labeled $\mathrm{CO}_{2}$ excretion after the tracer infusion was stopped, both at rest (Fig. 2) and during exercise (Fig. 5). Although this would not affect calculations of FFA appearance or disappearance rates, label fixation would cause the underestimation of isotopically determined plasma FFA oxidation rates, by decreasing the apparent rate of labeled $\mathrm{CO}_{2}$ production $(18,23)$, and as a consequence would cause the overestimation of the calculated intracellular fatty acid oxidation rate. Thus, our data indicate that, as currently used, tracer estimates of plasma FFA oxidation are not valid. This implies that results from studies using tracer techniques alone or in combination with indirect calorimetry to estimate plasma and intracellular fatty acid oxidation (1-9), have likely underestimated the true value of plasma FFA oxidation.

To directly test the role of the TCA cycle exchange reactions in label fixation we demonstrated the potential magnitude of these reactions by infusion of $\left[1,2-{ }^{13} \mathrm{C}\right]$ acetate (protocol 2 ) and then confirmed that these findings applied to fatty acids by infusion of $\left[\mathrm{U}-{ }^{13} \mathrm{C}\right]$ palmitate at rest (protocol 3 ). We estimated that after $30 \mathrm{~min}$ of $\left[1,2-{ }^{13} \mathrm{C}\right]$ acetate infusion $\sim 14 \%$ of the label in acetate ended up in glutamate/glutamine and lactate/ pyruvate. This reflects the minimum amount of label that can be fixed via TCA cycle exchange reactions, since label could also be in glucose, aspartate, and perhaps other products. Whereas we found no detectable isotopic enrichment in glucose during the 30-min infusion, this probably reflects the slow turnover time of the glucose pool, relative to the rate and duration of the acetate infusion. Thus, it is likely that at least $14 \%$ of the label in palmitate is also expected to be fixed via these exchange reactions, since labeled acetyl-CoA should be treated the same regardless of whether it is coming from acetate or palmitate.

Protocol 3 provided further support for the importance of TCA cycle exchange reactions. We found that during infusion of labeled palmitate plasma glutamate and breath ${ }^{13} \mathrm{CO}_{2}$ enrichment significantly increased shortly after the initiation of tracer infusion (Fig. 4). The only pathway by which label from palmitate can end up in glutamate is via exchange reactions occurring after palmitate-derived labeled acetyl-CoA has entered the TCA cycle (Fig. 1). To further evaluate the role of exchange reactions during labeled fatty acid infusion, we infused labeled pal- mitate and acetate during exercise (protocol 4). Exercise increases TCA cycle activity severalfold over the activity of the exchange reactions, because the rates of glutamate formation and gluconeogenesis are no where near as great as is total TCA cycle activity $(25,26)$; thus, if label fixation occurs via TCA cycle exchange reactions, then palmitate- and acetate-derived labeled $\mathrm{CO}_{2}$ would decay significantly faster during exercise as compared to rest. We found that the decay rates of labeled $\mathrm{CO}_{2}$ increased severalfold during exercise, as compared to rest (Table I). This increase cannot be explained merely by the two to threefold increase in FFA flux expected as a result of exercise (27). Furthermore, the increase in plasma glutamate/glutamine enrichment during exercise was significantly less than the increase at rest (data not shown), indicating that less label is lost via TCA cycle exchange reactions during exercise as compared to rest. The diminished increase in plasma glutamate/glutamine enrichment during exercise cannot be due to increased appearance of glutamate (25). These findings support the notion that exchange reactions in the TCA cycle are the major site of label fixation during infusion of fatty acid tracers.

Account cannot be taken of exchange reactions in the TCA cycle by the so-called bicarbonate correction factor. Further, the extent of underestimation of the true rate of oxidation will depend on the rate of the TCA cycle in relation to the rate of the exchange reactions. For example, an increase in insulin concentration might decrease the rate of the gluconeogenic pathway in relation to the TCA cycle, thereby indicating an apparent increase in the efficiency of plasma FFA oxidation because less label would be lost from the OAA pool. Similarly, if the TCA cycle rate increases in relation to the rate of the exchange reactions, as is the case during exercise, less label would be lost via exchange reactions and thus the magnitude of the underestimation of plasma FFA oxidation would be expected to be less. Another problem stemming from the movement of the label from the TCA cycle into other pathways is reflected by the slow decay in enrichment after the tracer infusion is stopped (Fig. 2 ). Since the label moves into pools which themselves may ultimately be oxidized, labeled $\mathrm{CO}_{2}$ will be produced in that process which will actually reflect fat oxidized at an earlier time. Thus, an experimental design which compares FFA oxidation in one state (e.g., basal) versus another state (e.g., hyperinsulinemic clamp) would require many hours until the breath $\mathrm{CO}_{2}$ enrichment reflected what is actually occurring during that perturbation, as opposed to what occurred several hours earlier. All of these problems make the traditional use of the tracer method to quantify plasma FFA oxidation questionable in both the quantitative and qualitative sense.

The fact that label fixation occurs after the entrance of acetyl-CoA into the TCA cycle suggests that the problem is not unique to isotopic determination of plasma FFA oxidation rates. Since all substrates, (i.e., carbohydrates, fats, and proteins ) have to enter the TCA cycle in order to be oxidized, if the label also enters the TCA cycle and is not lost to reactions before the entrance of acetyl-CoA into the TCA cycle, then it is expected that the isotopically determined oxidation rate of the particular substrate would be an underestimate of the true oxidation rate. The position of the label on acetyl-CoA, at the one (C-1) or the two (C-2) position, will also affect the extent of label fixation, since there is much greater chance that label in the C-2 position will be lost in the pathways mentioned above, than would label in the $\mathrm{C}-1$ position. This problem has been previously discussed in relation to other substrates (18). 
In summary, our data suggest that plasma FFA entering cells, destined to be oxidized, are transported directly to the mitochondria for oxidation. Label fixation observed during FFA tracer infusion occurs not only via the bicarbonate pool, but also via isotopic exchange reactions in the TCA cycle. Tracer techniques as currently used therefore do not accurately reflect plasma FFA oxidation.

\section{Acknowledgments}

The authors gratefully appreciate the cooperation of the volunteers and the assistance of Drs. Samuel Klein, Xiao-Jun Zhang, Yoichi Sakurai, and Hidefumi Baba, and the nursing staff of the Clinical Research Center in the performance of the experiments. We thank Dr. Yaoqing Zheng, Yun-Xia Lin, Yanping Sun, and Guy Jones for excellent technical assistance, David Chinkes for discussion of the calculations, and Dr. Lyle Broemeling for assistance with the statistical analysis.

This work was supported by National Institutes of Health grants GCRC-00073, DK-34817, and DK-46017, and Shriners Hospital grant 15849. Labros S. Sidossis was an Alexander S. Onassis Foundation Scholar.

\section{References}

1. Groop, L. C., R. C. Bonadonna, S. DelPrato, K. Ratheiser, K. Zyck, E. Ferrannini, and R. A. DeFronzo. 1989. Glucose and free fatty acid metabolism in non-insulin-dependent diabetes mellitus. Evidence for multiple sites of insulin resistance. J. Clin. Invest. 84:205-213.

2. Groop, L. C., R. C. Bonadonna, M. Shank, A. S. Petrides, and R. A. DeFronzo. 1991. Role of free fatty acids and insulin in determining free fatty acid and lipid oxidation in man. J. Clin. Invest. 87:83-89.

3. Groop, L. C., R. C. Bonadonna, D. C. Simonson, A. S. Petrides, M. Shank, and R. A. DeFronzo. 1992. Effect of insulin on oxidative and nonoxidative pathways of free fatty acid metabolism in human obesity. Am. J. Physiol. 263:E79E84.

4. Bonadonna, R. C., L. C. Groop, K. Zych, M. Shank, and R. A. DeFronzo 1990. Dose-dependent effect of insulin on plasma free fatty acid turnover and oxidation in humans. Am. J. Physiol. 259:E736-E750.

5. Yki Jarvinen, H., I. Puhakainen, C. Saloranta, L. Groop, and M. R. Taskinen. 1991. Demonstration of a novel feedback mechanism between FFA oxidation from intracellular and intravascular sources. Am. J. Physiol. 260:E680-E689.

6. Havel, R. J., A. Naimark, and C. F. Borchgrevink. 1963. Turnover rate and oxidation of free fatty acids of blood plasma in man during exercise: studies during continuous infusion of palmitate-1-C ${ }^{14}$. J. Clin. Invest. 42:1054-1063.

7. Havel, R. J., B. Pernow, and N. L. Jones. 1967. Uptake and release of fatty acids and other metabolites in legs of exercising men. J. Appl. Physiol. 23:9099.

8. Hagenfeldt, L., and J. Wahren. 1968. Human forearm muscle metabolism during exercise. II Uptake, release and oxidation of FFA and glycerol. Scand. $J$. Clin. Lab. Invest. 21:263-276.

9. Ahlborg, G., P. Felig, L. Hagenfeldt, R. Hendler, and J. Wahren. 1974. Substrate turnover during prolonged exercise in man. Splanchnic and leg metabolism of glucose, free fatty acids and amino acids. J. Clin. Invest. 53:1080-1090.

10. Dagenais, G. R., R. G. Tancredi, and K. L. Zierler. 1976. Free fatty oxidation by forearm muscle at rest, and evidence for an intramuscular lipid pool in the human forearm. J. Clin. Invest. 58:421-431.

11. Hagenfeldt, L., and J. Wahren. 1972. Human forearm muscle metabolism during exercise. VII. FFA uptake and oxidation at different work intensities. Scand. J. Clin. Lab. Invest. 30:429-436.

12. Wolfe, R. R., M. J. Durkot, and M. H. Wolfe. 1981. Investigation of kinetics of integrated metabolic response to adrenergic blockade in conscious dogs. Am. J. Physiol. 241:E385-E395.

13. Heiling, V. J., J. M. Miles, and M. D. Jensen. 1991. How valid are isotopic measurements of fatty acid oxidation? Am. J. Physiol. 261:E572-E577.

14. Havel, R. J., J. M. Felts, and C. M. Van Duyne. 1962. Formation and fate of endogenous triglycerides in blood plasma of rabbits. J. Lipid Res. 3:297-308.

15. Goransson, G., and T. Olivecrona. 1964. The metabolism of fatty acids in the rat. Acta Physiol. Scand. 62:224-239.

16. Strisower, E. G., G. D. Kohler, and I. L. Chaikof. 1952. Incorporation of acetate carbon into glucose by liver slices from normal and alloxan diabetic rats. J. Biol. Chem. 198:115-126.

17. Krebs, H. A., R. Hems, M. Weidemann, and R. Speake. 1966. The fate of isotopic carbon in kidney cortex synthesizing glucose from lactate. Biochem. J. 101:242-249.

18. Wolfe, R. R., and F. Jahoor. 1990. Recovery of labeled $\mathrm{CO}_{2}$ during the infusion of C-1- vs C-2-labeled acetate: implications for tracer studies of substrate oxidation. Am. J. Clin. Nutr. 51:248-252.

19. Schumann, W. C., I. Magnusson, V. Chandramouli, K. Kumaran, J. Wahren, and B. R. Landau. 1991. Metabolism of $\left[2-{ }^{14} \mathrm{C}\right]$ acetate and its use in assessing hepatic Krebs cycle activity and gluconeogenesis. J. Biol. Chem. 266:6985-6990.

20. Magnusson, I., W. C. Schumann, G. E. Bartsch, V. Chandramouli, K. Kumaran, J. Wahren, and B. R. Landau. 1991. Noninvasive tracing of Krebs cycle metabolism in liver. J. Biol. Chem. 266:6975-6984.

21. Consoli, A., F. Kennedy, J. Miles, and J. Gerich. 1987. Determination of Krebs cycle metabolic carbon exchange in vivo and its use to estimate the individual contribution of gluconeogenesis and glycogenolysis to the overall glucose output in man. J. Clin. Invest. 80:1303-1310.

22. Havel, R. J., L.-G. Ekelund, and A. Holmgren. 1967. Kinetic analysis of the oxidation of palmitate- $1-{ }^{14} \mathrm{C}$ in man during prolonged heavy muscular exercise. $J$. Lipid Res. 8:366-373.

23. Wolfe, R. R., J. E. Evans, C. J. Mullany, and J. F. Burke. 1980. Measurement of plasma free fatty acid turnover and oxidation using $\left[1-{ }^{13} \mathrm{C}\right]$ palmitic acid Biomed. Mass Spectrom. 7:168-171.

24. Issekutz, B., B. Paul, H. I. Miller, and W. M. Bortz. 1968. Oxidation of plasma FFA in lean and obese humans. Metab. Clin. Exp. 17:62-73.

25. Williams, B., D. Chinkes, T. D. Kimbrough, F. Jahoor, and R. R. Wolfe 1991. Comparison of alanine and glutamine kinetics in exercising humans. Med. Sci. Sports Exercise. 23:S37. (Abstr.)

26. Coggan, A. R. 1991. Plasma glucose metabolism during exercise in humans. Sports Med. 11:102-124.

27. Romijn, J. A., E. F. Coyle, L. S. Sidossis, A. Gastaldelli, J. F. Horowitz, E. Endert, and R. R. Wolfe. 1993. Regulation of endogenous fat and carbohydrate metabolism in relation to exercise intensity and duration. Am. J. Physiol. 265:E380-E391.

28. Chinkes, D. L., X.-J. Zhang, J. A. Romijn, Y. Sakurai, and R. R. Wolfe 1994. Measurement of pyruvate and lactate kinetics across the hindlimb and gut of anesthetized dogs. Am. J. Physiol. 267:E174-E182.

29. Wolfe, R. R. 1984. Tracers in Metabolic Research: Radioisotope and Stable Isotope/Mass Spectrometry Methods. Alan R. Liss, Inc., New York. 246 pp.

30. Wolfe, R. R. 1992. Radioactive and Stable Isotope Tracers in Biomedicine. Wiley-Liss Inc., New York. 422 pp.

31. Wolfe, R. R., F. Jahoor, and H. Miyoshi. 1988. Evaluation of the isotopic equilibration between lactate and pyruvate. Am. J. Physiol. 254:E532-E535.

32. Hellerstein, M. K., M. Christiansen, S. Kaempfer, C. Kletke, K. Wu J. S. Reid, K. Mulligan, N. S. Hellerstein, and C. H. L. Shackleton. 1991. Measurement of de novo hepatic lipogenesis in humans using stable isotopes. J. Clin. Invest. 87:1841-1852.

33. Wolfe, R. R. S. Klein, F. Carraro, and J. M. Weber. 1990. Role of triglyceride-fatty acid cycle in controlling fat metabolism in humans during and after exercise. Am. J. Physiol. 258:E382-E389.

34. Malmendier, C. L., C. Delcroix, and M. Berman. 1974. Interrelations in the oxidative metabolism of free fatty acids, glucose, and glycerol in normal and hyperlipemic patients. J. Clin. Invest. 54:461-476.

35. Wisneski, J. A., E. W. Gertz, R. A. Neese, and M. Mayr. 1987. Myocardia metabolism of free fatty acids. Studies with ${ }^{14} \mathrm{C}_{1}$-labeled substrates in humans. $J$. Clin. Invest. 79:359-366. 